\title{
NILAI-NILAI SOSIAL YANG TERKANDUNG DALAM UNGKAPAN KASUNGKI PADA MASYARAKAT MUNA DESA KAROO KECAMATAN KONTUKOWUNA
}

\author{
Harnifa ${ }^{1}$,Haerun Ana ${ }^{2}$, dan La Niampe ${ }^{3}$ \\ pbsi.fkip.uho@gmail.com \\ 1,2,3, Jurusan Pendidikan Bahasa dan Sastra Indonesia, \\ Fakultas Keguruan dan Ilmu Pendidikan, Universitas Halu Oleo \\ Kampus Hijau Bumi Tridharma Anduonohu, Kendari, Indonesia
}

\begin{abstract}
ABSTRAK
Tujuan dari penelitian ini adalah untuk mendeskripsikan dan menganalisis nilainilai sosial yang terkandung dalam ungkapan Kasungki pada Masyarakat Muna Desa Karoo Kecamatan Kontukowuna.Penelitian ini merupakan penelitian lapangan.Metode yang digunakan dalam penelitian ini adalah metode deskriptif kualitataif. Data dalam penelitian ini adalah data yang berupa bahasa lisan yang dituturkan secara langsung oleh orang tua (pemangku adat). Sumber data dalam penelitian ini adalah diperoleh dari pemangku adat dan masyarakat asli Desa Karoo Kecamatan Kontukowuna. Teknik pengumpulan data yang digunakan dalam penelitian ini adalah teknik observasi, wawancara, rekam,dan simak catat. Hasil dalam penelitian ini diperoleh dari nilai-nilai sosial yang terkandung dalam ungkapan kasungkipada masyarakat Muna Desa Karoo Kecamatan Kontukowuna yang meliputi 1. bekerjasama, 2.pedulinasib orang lain, 3. sukamendoakan orang lain.
\end{abstract}

Kata kunci: kasungki; nilai; nilai sosial,

184 | Jurnal BASTRA (Bahasa dan Sastra), Vol. 5 No.2, Edisi April 2020/e-ISSN: 25033875 /http://ojs.ohu.ac.id/index.php/BAS 


\begin{abstract}
The purpose of this study is to describe and analyze the social values contained in the Kasungki expression in the Muna Community of Karoo Village, Kontukowuna District. This research is a field research. The method used in this research is descriptive qualitative method. The data in this study are data in the form of spoken language which is spoken directly by parents (customary stakeholders). Sources of data in this study were obtained from customary and indigenous stakeholders in Karoo Village, Kontukowuna District. The data collection techniques used in this study were observation, interview, record, and note taking techniques. The results in this study were obtained from the social values contained in the expression of kasungki in the Muna Village Karoo community, Kontukowuna District which includes 1. cooperation, 2. care for the fate of others, 3. like to pray for others.
\end{abstract}

Keywords: kasungki; value; social value

185 | Jurnal BASTRA (Bahasa dan Sastra), Vol. 5 No.2, Edisi April 2020/e-ISSN: 25033875 /http://ojs.ohu.ac.id/index.php/BAS 


\section{PENDAHULUAN}

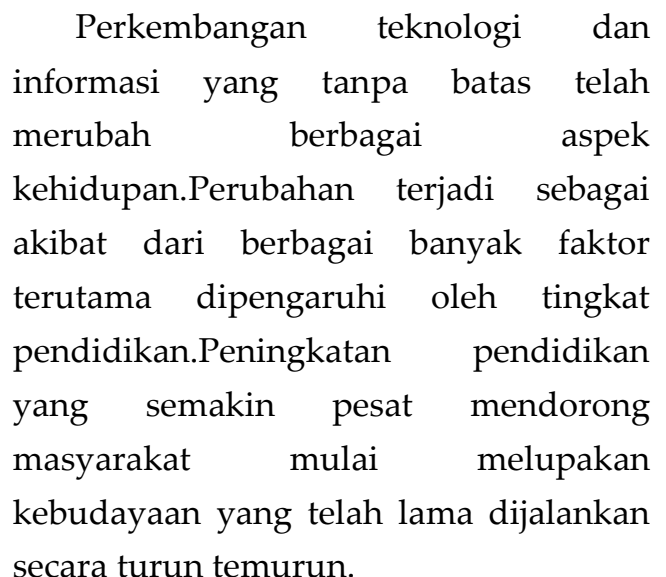

Indonesia adalah salah satu negara yang terdiri dari berbagai suku bangsa. Dengan demikian, maka lahirlah berbagai kebudayaan yang berbeda pula di tiap daerahnya. Keanekaragaman kebudayaan menjadikan Indonesia sebagai salah satu bangsa yang kaya akan budaya di tiap daerahnya. Kebudayaan yang lahir dari tiap daerah inilah yang dipadukan dalam pengembangan kebudayaan nasional.

Kebudayaan nasional merupakan kebudayaan yang terbentuk dari keseluruhan budaya daerah yang berkembang dalam kehidupan masyarakat Indonesia serta hasil serapan dari budaya asing atau global, dengan ikatan yang menjadi ciri khas seluruh budaya di Indonesia yaitu nilai-nilai leluhur bangsa Indonesia. Kebudayaan nasional diharapkan mampu memberikan kontribusi terhadap kemajuan bangsa Indonesia sehingga mendorong bangsa Indonesia menjadi salah satu bangsa yang memiliki akar budaya sehingga mampu membedakannya dengan bangsa lain.

Kebudayaan nasional tidak terlepas dari upaya penggalian kebudayaan daerah yang tersebar diseluruh wilayah tanah air. Kebudayaan daerah merupakan kebudayaan yang berkembang di daerah-daerah dan merupakan milik suku-suku bangsa yang berada di wilayah nusantara. Salah satu wilayah yang memiliki kebudayaan daerah adalah Sulawesi Tenggara. Sulawesi Tenggara adalah salah satu provinsi yang terdiri dari berbagai suku yang mendiaminya seperti suku Muna, Tolaki dan Buton.

Suku-suku yang mendiami Sulawesi Tenggara kemudian membentuk sebuah lingkungan yang memiliki kebudayaan yang terbentuk dari tradisi tiap suku. Tradisi adalah kebiasaan yang secara turun temurun dan menjadi bagian dari kehidupan suatu kelompok masyarakat. Tradisi inilah yang menjadi ajang silaturahim masyarakat daerah pedesaan yang masih kental dengan pengadaan berbagai tradisi yang dilakukan secara turun temurun. Salah satunya adalah tradisi lisan yang merupakan kebiasaan yang diwariskan secara lisan dari tiap generasi dan tidak didokumentasikan atau dipublikasikan secara umum.

Suku Muna merupakan salah satu suku yang memiliki tradisi lisan yang berbeda pula dengan suku Tolaki maupun Buton. Salah satunya adalah tradisi pada proses pelaksanaan kasungki yang terdapat pada masyarakat Muna Desa Karoo Kecamatan Kontukowuna.

Tradisi kasungki dilakukan pada anak-anak yang terdiri atas beberapa anak perempuan dan laki-laki. Kasungki dilakukan jika ada anak yang diyakini terlambat dalam pertumbuhan seperti sering sakit atau hal-hal yang 
berhubungan dengan mitos atau hal-hal ghaib lainnya yang diistilahkan dengan terjepit papan. Sehingga orang tua anak beranggapan bahwa harus diadakan kasungki. proses pelaksanaa kasungki melibatkan masyarakat secara umum untuk bekerjasama demi terlaksananya kasungki. Kerjasama inilah yang diharapkan mampu membangun hubungan sosial antar masyarakat Desa Karoo kecamatan Kontukowuna.

Pelaksanaan kasungki memiliki makna dan fingsi bagi masyarakat Muna Desa Karoo Kecamatan Kontukowuna yang saat ini perlahan terlupakan sebagai akibat dari kurangnya kepercayaan dan pemahaman masyarakat akan nilai dari kasungki. Dengan demikian, lambat laun tradisi kasungki akan mengalami kepunahan secara menyeluruh.

Berawal dari kondisi tersebut, hal ini sangat menarik perhatian peneliti untuk melakukan penelitian dengan judul “Nilai-nilai Sosial yang Terkandung dalam Ungkapan Kasungki pada Masyarakat Muna Desa Karoo Kecamatan Kontukowuna “. Penelitian ini akan menghasilakan nilai-nilai sosial yang terkandung dalam ungkapan kasungki pada masyarakat Muna Desa Karoo Kecamatan Kontukowuna

Berdasarkan latar belakang di atas, maka permasalahan dalam penelitian ini adalah sebagai berikut:

a. Bagaimanakah nilai-nilai sosial yang terkandung dalam ungkapan kasungki pada masyarakat Muna desa Karoo kecamatan Kontukowuna. b. Bagaimanakah nilai-nilai sosial yang terkandung dalam ungkapan kasungki pada masyarakat Muna desa Karoo kecamatan Kontukowuna

Adapun tujuan dari penelitian ini yaitu sebagai berikut:

a. Mendeskripsikan nilai-nilai sosial yang terkandung dalam ungkapan kasungki pada masyarakat Muna desa Karoo kecamatan Kontukowuna.

b. Menganalisis nilai-nilai sosial yang terkandung dalam ungkapan kasungki pada masyarakat Muna desa Karoo kecamatan Kontukowuna.

Adapun manfaat dari penelitian ini yaitu sebagai berikut:

a. Pembaca sebagai penikmat sastra akan lebih memahami nilai-nilai sosial yang terkandung dalam ungkapan kasungki pada masyarakat Muna desa Karoo kecamatan Kontukowuna.

b. Sebagai bahan masukan dan bahan informasi bagi usaha pembangunan dan pelestarian sastra daerah.

c. Sebagai upaya yang bermanfaat dalam rangka membangkitkan kembali daya apresiasi sastra daerah.

d. Sebagai sumbangan pemikiran dan bahan-bahan perbandingan pada penelitian lain yang sejalan dengan penelitian ini.

Metode yang digunakan dalam penelitian ini adalah metode deskriptif kualitatif.Menurut Sttrauss dan Corbin (dalam Sujarweni, 2014: 19) yang dimaksud dengan penelitian kualitatif

187 | Jurnal BASTRA (Bahasa dan Sastra), Vol. 5 No.2, Edisi April 2020/e-ISSN: $25033875 /$ http://ojs.ohu.ac.id/index.php/BAS 
adalah jenis penelitian yang menghasilkan penemuan-penemuan yang tidak dapat dicapai (diperoleh) dengan menggunakan prosedurprosedur statistik atau cara-cara lain dari kuantifikasi (pengukuran).Penelitian kualitatif secara umum dapat digunakan untuk penelitian tentang kehidupan masyarakat, sejarah, tingkah laku, fungsionalisasi organisasi, aktivitas sosial, dan lain-lain.

Jenis penelitian ini adalah penelitian lapangan. Penelitian lapangan merupakan suatu bentuk penelitian yang dilakukan dengan cara peneliti turun langsung dilapangan untuk mendapatkan data yang valid mengenai obyek yang akan diteliti. Dalam hal ini mengenai nilai-nilai sosial yang terkandung dalam proses pelaksanaan kasungki pada masyarakat Muna desa Karoo kecamatan Kontukowuna.

Data yang digunakan dalam penelitian ini adalah data yang berupa bahasa lisan yang dituturkan secara langsung oleh orang tua (pemangku adat) yang mengetahui dan memahamai secara detail mengenai makana dan fungsi yang terkandung dalam proses pelaksanaan kasungki.

Sumber data diperoleh dari pemangku adat dan masyarakat asli Desa Karoo Kecamatan Kontukowuna. Dengan demikian, dalam penentuan informan diharapakan dapat mengetahui masalah penelitian. Oleh karena itu, dalam menentukan informan sesuai dengan kriteria sebagai berikut :

1. Pemangku adat yang terbiasa memimpin kasungki
2. Penduduk asli Desa Karoo Kecamatan Kontukowuna yang masih menjalankan tradisi kasungki. Pengumpulan data dilakukan dengan menggunakan teknik observasi, wawancara, rekam,dan simak catat. Hal ini dilakukan untuk memperkuat bukti bahwa data yang ada sesuai dengan kenyataan dilapangan.

1. Teknik observasi. Teknik pengumpulan data dengan observasi merupakan sebuah teknik dimana peneliti turun langsung ke lapangan untuk bertemu pemangku adat yang akan dijadikan informan sesuai dengan kriteria informan yang telah ditetapkan. Dalam hal ini informan yang mampu memberikan penuturan tentang unkapan kasungki yang berlaku di Desa Karoo Kecamatan Kontukowuna.

2. Teknik wawancara. Setelah mendapatkan informan yang sesuai dengan kriteria yang telah ditentukan sebelumnya, maka dilakukan kegiatan wawancara. Wawancara merupakan sebuah kegiatan dimana peneliti menanyai informan terkait obyek yang akan diteliti. Teknik ini digunakan karena data yang dibutuhkan dalam penelitian ini berupa data lisan yang tersebar di kalangan masyarakat Muna desa Karoo Kecamatan Kontukowuna. Oleh karena itu, untuk mengumpulkan data tersebut harus diadakan pertanyaan secara lisan agar informan dapat menuturkan dan bercerita mengenai obyek yang akan diteliti.

188 | Jurnal BASTRA (Bahasa dan Sastra), Vol. 5 No.2, Edisi April 2020/e-ISSN: 25033875 /http://ojs.ohu.ac.id/index.php/BAS 
3. Teknik Rekam. Teknik rekam digunakan pada saat kegitan wawncara berlangsung. Teknik ini digunakan dengan pertimbangan bahwa data yang diteliti berupa data lisan. Oleh sebab itu, data-data berupa ungkapan Kasungki

Teknik simak catat. Teknik ini digunakan untuk memperoleh data dengan cara memperhatikan, kemudian mencatat pembicaraan atau informasi dari informan sebagai data yang digunakan dalam penelitian

Teknik analisis data yang digunakan dalam penelitian ini adalah deskriptif.Data yang dideskripsikan dalam bentuk kata-kata atau kalimat yakni menguraikan makna dan fungsi pelaksanaan kasungki pada masyarakat Muna desa Karoo kecamatan Kontukowuna.

Analisis data menggunakan pendekatan struktural yaitu pendekatan yang mengandung karya sastra terjadi atas seperangkat struktur yang berhubungan satu sama lainya dan kemudian dengan menggunakan prosedur sebagai berikut:

a. Transkripsi, data yang direkam didengarkan kembali lalu dicatat sesuai dengan bait dan barisnya.

b. Terjemahan, setelah naskah rekaman disusun berdasarkan bait dan barisnya dalam bentuk tertulis, selanjutnya diterjemahkan dalam bahasa Indonesia dengan menggunakan terjemahan secara bebas dengan arti dan makna yang mudah dipahamai.

c. Analisis, data yang telah disusun lalu dianalisis dengan cara mendeskripsikan ungkapan yang terkandung dalam kasungki . menguraikan makna dan fungsi pelaksanaan kasungki pada masyarakat Muna desa Karoo kecamatan Kontukowuna.

\section{HASIL DAN PEMBAHASAN}

Deskripsi Ungkapan Kasungki pada Masyarakat Muna Desa Karoo camatan Kontukowuna

Kasungki merupakan tradisi yang dilakukan secara turun temurun oleh masyarakat Muna di Desa Karoo Kecamatan Kontukowuna.Hal ini diberlakukan terhadap anak-anak yang diyakini mengalami pertumbuhan lambat atau kurang normal. Sesuai hasil wawancara penelitian dengan informan (pemangku adat) atau pomantoto dalam bahasa Muna bahwa proses terjadinya kasungki dalam sebuah keluarga apabila anaknya sering sakit dan telah diobati berbagai macam pengobatan baik medis maupun tradisional namun tidak mengalami perubahan atau kesembuhan. Hal ini menyebabkan orang tua memiliki inisiatif atau keyakinan bahwa anak tersebut noghatie dopi (terjepit papan) sehingga harus diadakan proses kasungki.

Pelaksanaan proses kasungki dilakukan dengan berbagai persiapan terutama menyiapkan alat dan bahan yang akan digunakan seperti dopi (papan), nuhua (panci tradisonal masyarakat Muna yang terbuat dari tanah liat digunakan untuk memasak), bhosu (wadah yang digunakan untuk mengambil air), ghue (rotan), ghai (kelapa), kalei fitufulu rawua (pisang 72

189 | Jurnal BASTRA (Bahasa dan Sastra), Vol. 5 No.2, Edisi April 2020/e-ISSN: 25033875 /http://ojs.ohu.ac.id/index.php/BAS 
buah), mafu (ubi tatas), Bhenu (sabut kelapa), roono kalei (daun pisang), kawera (pecahan nuhua yang digunakan sebagai pengganti wajan atau kuali), kaghula(obor), ganda (gendang), suli (seruling bambu), mbololo (gong), koroka (lidi enau), raghanolele (dahan beringin), raghanokapa (dahan kapas), kantofi (alat pengukus), sere (cerek), kaleintinipughu (satu pohon pisang).

Analisis nilai-nilai sosial yang Terkandung dalam Ungkapan Kasungki pada Masyarakat Muna Desa Karoo Kecamatan Kontukowuna

Kerjasama adalah proses pelaksanaan segala macam aktivitas yang diselesaikan secara bersama-sama. Hal ini dikarenakan manusia sebagai mahluk sosial yang memerlukan bantuan orang lain dalam setiap kegiatan kesehariaannya. Oleh karena itu, dengan adanya pelaksanaan kegiatan secara bersama-sama diharapkan dapat mempermudah dan mempercepat proses pekerjaan karena dilakukan secara bersama-sama. Selain itu, pelaksanaan kegiatan secara bersama-sama dapat pula meningkatkan hubungan kekeluargaan dalam lingkungan masyarakat secara menyeluruh.

Peningkatan hubungan kerjasama dalam masyarakat akan melahirkan kehidupan yang harmonis dan saling menghargai. Hal ini dikarenakan tiaptiap individu merasa dibutuhkan oleh individu lain dalam kedudukannya sebagai masyarakat. Hal inilah yang juga terjadi dalam pelaksanaan kasungki, dimana masyarakat akan bekerjasama agar proses kasungki dapat berjalan sesuai dengan kebiasaan yang selama ini dilakukan.

Pelaksanaan kasungki mengandung nilai sosial berupa kerjasama antaramasyarakat Desa Karoo dengan yang memiliki acara, yaitu sebagai berikut :

"Pada anagha kokarabuno debhasimo miehi welono kampo atau welono liwu mbali mealahino nimokae mefotokano sonipake daesungki nando mealano dopi, nando mealano onuhua, nando melano bhosu, oghue, oghai, kalei fitufulu rawua, mafu, bhenu, roono kalei, kawera, kaghula, ganda, suli, mbololo, ragahano lele, ragahano kapa, okantofi, sere, kalei ntinipughu nonando kawu bahra-bhara bhe alati angha dofonandoe welolambu dofotokaem kasungki nagha dojalangiem fato gholeo fato alo".

Setelah itu yang memiliki acara akan memanggil orang-orang yang ada didalam kampung atau masyarakat yang ada di Desa Karoo untuk saling membantu mencari alat dan bahan yang akan dipakai pada saat proses pelaksanaan kasungki. Masyarakat akan mengumpulkan alat dan bahan yang akan digunakan seperti mengambil papan, kendi, rotan, kelapa, pisang sebanyak 72 buah, ubi tatas, tempurung kelapa, daun pisang, pecahan kendi, obor, gendang, seruling, gong, dahan pohon beringin, dahan pohon kapas, kerucut, dan cerek".

Kutipan di atas menunjukan betapa pentingnya kerjasama masyarakat dalam menyiapkan berbagai peralatan yang akan digunakan dalam proses kasungki. Masyarakat tanpa

190 | Jurnal BASTRA (Bahasa dan Sastra), Vol. 5 No.2, Edisi April 2020/e-ISSN: 25033875 /http://ojs.ohu.ac.id/index.php/BAS 
diminta secara resmi akan mulai mengumpulkan peralatan tersebut sesuai dengan permintaan orang tua anak yang akan dikasungki. Mereka memiliki tingkat kesadaran yang begitu tinggi untuk saling membantu demi kelangsungan proses kasungki. Dengan demikian, proses kasungki memiliki nilai sosial berupa kerjasama dalam masyarakat Desa Karoo.

Masyarakat adalah kumpulan orangorang yang mendiami suatu wilayah tertentu. Dalam kehidupan bermasyarakat, terdapat hubungan kerjasama antara individu satu dengan yang lain. Hal ini tentu akan memunculkan kepedulian dari tiap orang akan nasib orang lain. Sikap peduli akan nasib orang lain berarti ikut merasakan apa yang dirasakan oleh orang lain. Misalnya, ketika orang lain terkena musibah maka sebagai masyarakat yang baik tentu kita akan ikut berusaha membantu mereka yang terkena musibah. Sikap peduli merupakan rasa simpati yang secara alamiah lahir dari tiap individu ketika melihat orang lain kesusahan atau mengalami musibah. Dengan adanya kepedulian akan nasib orang lain, terlebih pada orang yang tidak mengenal kita sama sekali, maka akan membuatnya tersentuh dan akan mendoakan kita agar selalu terhindar dari kesusahan. Dengan demikian, sikap peduli akan nasib orang lain perlu ditanamkan sejak dini agar selalu tercipta kebaikan dalam setiap langkah dikehidupan kita.

Peduli akan nasib orang lain, juga dirasakan dalam proses pelaksanaan kasungki. Hal ini dapat dilihat dari sikap tetangga atau orang-orang yang melihat anak atau keluarga kita yang mengalami masalah dalam pertumbuhannya. Mereka akan menyarankan kita untuk melaksanakan proses kasungki untuk menyembuhkan si anak.

"Kasungki bha-bhahano dorabue rampahano welo seghonu lambu dokoanagho robhine bhe dokoana moghane bahi rudua moghane semie robhine bahai rudua robhine semie moghane maka sasaki-saki mina bhe kaghosa. Dowulem dolili ane defeagoe kamokulano sabhara kaago dosobae doago ane kaago daga bhe kaago wuna taaka mina bhe kaghosa. Nandomo tetanggahi bisarano bahi anahi mosakino nagha tabea dasumungkie rampahano doworae nodai wuluno saranga-ranga, dadi kamokulano anahi mosakino nagha nebhasimo pomantoto sodasumungkigho anahi nagha".

"Proses pelaksanaan kasungki dilakukan apabila didalam suatu kelurga ada anak yang sakit tidak pernah sembuh. Orang tua si anak melakukan berbagai macam cara pengobatan mulai dari pengobatan medis hingga pengobatan tradisional Muna tetapi tidak ada kesembuhan. Hingga ada tetangga melihat kondisi anak tersebut bahwa anak yang sakit itu sebaiknya dikasungki karena melihat pertumbuhannya kurang normal tidak seperti pertumbuhan anak pada umumnya. Melihat kondisi itu orang tua si anak memanggil pemangku adat untuk melakukan kasungki terhadap anak yang sakit".

191 | Jurnal BASTRA (Bahasa dan Sastra), Vol. 5 No.2, Edisi April 2020/e-ISSN: 25033875 /http://ojs.ohu.ac.id/index.php/BAS 
Kutipan tersebut menunjukan bahwa, masyarakat memiliki sikap kepedulian yang sangat tinggi terhadap orang lain termasuk orang tua si anak. Mereka mengingatkan sekaligus mengusulkan apa yang menurut mereka bisa dilakukan untuk penyembuhan si anak. Selain itu, tetangga tidak hanya menolong orang yang sakit disekitaran rumanhnya tetapi siapapun orang ataupun masyarakat yang ada Desa Karoo Kecamatan Kontukowuna harus saling mengingatkan untuk kebaikan bersama.

Sikap peduli akan nasib orang lain yang terkandung dalam proses kasungki perlu terus dikembangkan dalam berbagai kegiatan masyarakat guna melahirkan masyarakat yang mampu merasakan kesusahan orang lain sehingga tercipta masyarakat yang memiliki tingkat kepedulian tinggi.

Manusia adalah mahluk yang diberi akal sehingga membedakannya dengan mahluk lain. Dengan akal, manusia akan mampu membedakan yang baik dan buruk. Akal sehat akan melahirkan pemikiran-pemikiaran yang baik sehingga menciptakan tindakan yang baik pula begitupun sebaliknya. Pemikiran-pemikiran yang dimiliki oleh manusia ini muncul dari dalam hati yang secara alamiah tergerak untuk membantu ataupun mendoakan orang lain.

Mendoakan orang lain merupakan suatu kegiatan yang dilakukan seseorang dengan memohon kepada Allah SWT agar orang lain diberi kemudahan dalam segala urusannya dalam menjalani kehidupan. Dengan mendoakan, menunjukan betapa kita ikut peduli dan prihatin akan nasib orang lain.

Kepedulian akan nasib orang lain memang ditunjukan dalam sikap ikut meringankan beban orang lain. Akan tetapi, mendoakan juga merupakan salah satu tindakan berusaha meringankan beban orang lain meski tidak berupa tindakan yang terlihat oleh kasat mata. Dengan mendoakan, diharapkan akan ada jalan keluar untuk membantu permasalahan orang lain.

Mendoakan orang lain untuk kebaikan, kesembuhan, ketentraman, atau hal-hal positif lainya merupakan hal baik yang patut ditunjukan oleh tiap individu dalam kehidupan bermasyarakat.Dalam proses pelaksanaan kasungki, juga terdapat nilai soisal berupa suka mendoakan orang lain yaitu tindakan pemangku adat atau pomantoto yang mendoakan anak yang akan dikasungki. Adapun kutipannya yakni :

"Koe kapunse-punse, koe kabhore-bhore, koe mansawu / ranga-ranga". Koe mosaki, naowolomo aitu ini sakimu, moghosamo koemo fendua, kafetompanomo aitu."

Artinya:

"Jangan idiot, jangan bodoh, jangan kurus (pertumbuhan tidak normal atau lambat dalam pertumbuhan).Jangan sakit, sembuh sekarang penyakitmu, sembuh jangan terulang, terakhir kalinya sekarang".

"Fondawu saki, saki patatipandehaono naowolomo aitu, nakumala anemo kawea, koemo nosuli-suli, name nero sau, name nekontu bhe name newite".

Artinya:

192 | Jurnal BASTRA (Bahasa dan Sastra), Vol. 5 No.2, Edisi April 2020/e-ISSN: 25033875 /http://ojs.ohu.ac.id/index.php/BAS 
Hilangkan penyakit, sakit yang tidak ditahu sembuh sekarang, pergi bersama angin, tidak kembali lagi, hinggap di daun, hinggap dibatu dan hinggap ditanah.

Kutipan di atas menunjukan kepedulian yang ditunjukan oleh pemangku adat terhadap anak yang akan dikasungki dengan memanjatkan doa agar si anak sembuh dari penyakitnya. Selain doa dari pemangku adat, orang lain yang ikut menghadiri proses kasungkipun ikut mendoakan dengan mengatakan :

"Sio-siomo omoghosamo ingka padamo doagoko". Naowolomo aitu ini sakimu, koemo moranga".

Artinya:

"Semoga cepat sembuh setelah diobati. Sembuh sekarang penyakitmu, jangan terlihat kurus lagi".

Kutipan ini menunjukan betapa orang lainpun ikut mendoakan anak yang akan dikasungki dengan ikhlas tanpa diminta oleh orang tua si anak.

3.

Penelitian ini menghasilkan kesimpulan bahwa kasungki merupakan tradisi yang dilakukan secara turun temurun oleh masyarakat Muna di Desa Karoo Kecamatan Kontukowuna yang diberlakukan terhadap anak-anak yang diyakini mengalami pertumbuhan lambat atau kurang normal

\subsection{Saran}

Beberapa saran yang dapat penulis berikan terkait dengan nilai-nilai sosial yang terkandung dalam proses pelaksanaan kasungki pada masyarakat
Muna
Desa
Karoo
Kecamatan

Kontukowuna bahwa nilai-nilai sosial yang terkandung dalam proses pelaksanaan kasungki perlu pula diterapkan dalam berbagai hal dalam kehidupan bermasyarakat guna menciptakan masyarakat yang mampu bekerjasama dalam menyelesaikan berbagai persoalan dengan menunjukan sikap peduli yang ditunjukan dalam bentuk tindakan nyata dan mendoakan orang lain yang ditunjukan dalam sikap yang tidak nyata namun mampu membantu orang lain.

193 | Jurnal BASTRA (Bahasa dan Sastra), Vol. 5 No.2, Edisi April 2020/e-ISSN: 25033875 /http://ojs.ohu.ac.id/index.php/BAS 


\section{DAFTAR PUSTKA}

Aisah, Susianti. 2015. Nilai-nilai Sosial yang Terkandung dalam Cerita Rakyat Ence Sulaiman pada Masyarakat Tomia. Jurnal Humanika. Vol 3 (15) 1-19.

Balawa, La Ode. 1991. Teori Sastra. Kendari: Unhalu.

Chaer, Abdul. 2012. Linguistik Umum. Jakarta: Rineka Cipta.

Duija, Nengah .2005. Tradisi Lisan, Naskah, Dan Sejarah. Jurnal Wacana. Vol 7 (2) Hal: 111-124.

Danandjaja. 1994. Folklor Indonesia. Jakarta: PT. Pustaka Utama Grafiti. Editorial, Padi .2013.Kumpulan Super Lengkap Sastra Indonesia.Jakarta : CV. Ilmu Padi Infra Pustaka Makmur

Endraswara, Suwardi .2013. Metodologi Penelitian Sastra. Yogyakarta : CAPS.

Faruk. 2012. Metode Penelitian Sastra. Yogyakarta : Pustaka Pelajar.

Fanani.1998. Struktur Sastra Lisan Wolio.Jakarta : Katalog Dalam Terbitan

Hoed, B.H. 2008.Komunikasi Lisan Sebagai

Dasar Tradisi Lisan (dalam Metodologi Kajian Tradisi Lisan). Jakarta: ATL.

(KDT).
Hutomo, Suripan Hadi. 1983. Panduan Penelitian Sastra Daerah. Jakarta : Depdikbud.

James. 1997. Folklor Indonesia. Jakarta : PT Pustaka Grafiti.

Kosasih, E. 2012.Dasar-dasar Keterampilan Bersastra. Bandung: Yrama Widya.

Marwati. 2015. Ungkapan Tradisional dalam Upacara Adat Perkawinan Masyarakat Bajo di Pulau Balu Kabupaten Muna Barat.jurnal humanika .Vol 3(15) Hal: 1-12.

Mustakim. 1997. Proyek Pembinaan Bahasa dan Sastra Indonesia dan Daerah

Pusat.Jakarta : KDT.

Parman, Hafid .2015.Tradisi Lisan Suku Bajo. Andonohu Kendari: Himpunan Sarjana Pendidikan Ilmu-Ilmu Sosial (HISPISI) Daerah Sultra.

Pateda, Mansoer. 2010. Sosiolinguistik. Gorontalo: Viladan.

Pudentia.2007. Hakikat Kelisanan dalam Tradisi Lisan Melayu Makyon. Depok: Fakultas Ilmu Pengetahuan Budaya.

Uniawati. 2006. Fungsi Mantra Melaut Pada Masyarakat Suku Bajo di Sulawesi Tenggara. Kendari:Katalog Dalam Terbitan (KDT).

Wicaksono, Andri. 2014. Pengkajian Prosa Fiksi. Jakarta: Garudahawaca.

Raharjo, Agung. 2009. Buku Kantong Sosiologi SMA IPS.Yogyakarta: Pustaka Widiyatma.

Rahmawati, 2014.Ungkapan Tradisional Muna.Kendari : Kantor Bahasa Provinsi Sulawesi Tenggara.

Semi, Atar. 1988. Anatomi Sastra. Padang: Angkasa.

194 | Jurnal BASTRA (Bahasa dan Sastra), Vol. 5 No.2, Edisi April 2020/e-ISSN: 25033875 /http://ojs.ohu.ac.id/index.php/BAS 
Sujarweni, Wiratna. 4014. Metodologi

Penelitian. Yogyakarta:

Pustakabarupress.

Sumardjo, Panuti. 1997. Apresiasi

Kesusastraan, Jakarta: Gramedia

Pustaka Utama.

Tomasoa, dkk. 2000. Sejarah dan

Perkembangan Sastra Indonesia di Maluku. Jakarta: Pusat Bahaa.

195 | Jurnal BASTRA (Bahasa dan Sastra), Vol. 5 No.2, Edisi April 2020/e-ISSN: 25033875 /http://ojs.ohu.ac.id/index.php/BAS 